Supplement of Solid Earth, 9, 573-598, 2018

https://doi.org/10.5194/se-9-573-2018-supplement

C Author(s) 2018. This work is distributed under

the Creative Commons Attribution 4.0 License.

(c) (1)

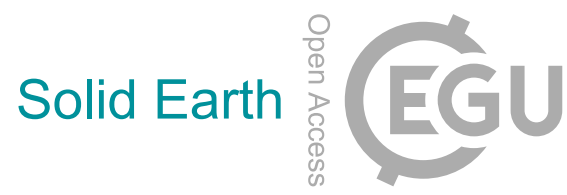

Supplement of

\title{
Sedimentary mechanisms of a modern banded iron formation on Milos Island, Greece
}

Ernest Chi Fru et al.

Correspondence to: Ernest Chi Fru (chifrue@cardiff.ac.uk)

The copyright of individual parts of the supplement might differ from the CC BY 4.0 License. 

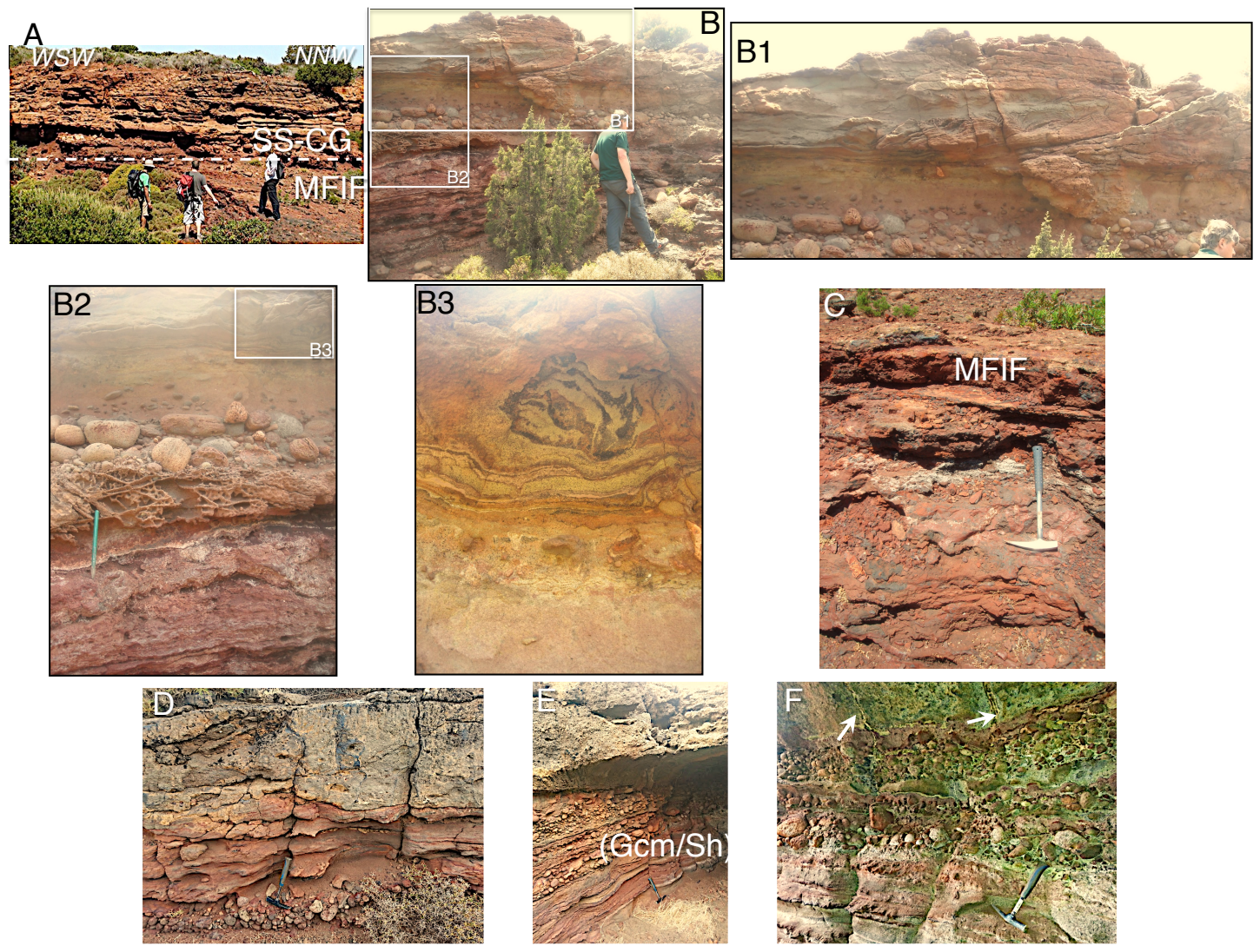

Supplementary Fig. 1. Field photographs from the Section A ("Litte Vani") outcrop. (A) Superposition of accumulation of sandstone-conglomerate facies (SS-CG) representative of high-energy conditions, on the quite background deposit represented by the MFIF, along an unconformity (dashed line). (B) Iron-rich massive to plane parallel-laminated sandstone/sandy tuff, clast-supported pebble-to-cobble conglomerate, greenish glauconite-bearing plane parallel-laminated sandstone/sandy tuff to laminated siltstone, and massive to planar cross-bedded to plane bedded sandstone/sandy tuff; (B1): Hummocky cross-stratification and loop bedding with inferred synsedimentary vertical brittle microfaults present in the upper plane parallellaminated sandstone to siltstone bed; (B2-B3): Convolute lamination, pseudonodule structures and flame structures. (C) Microfossiliferous iron formation (MFIF). (D-E) Fe-rich sandstone-conglomerate sequence unconformably overlain by Mn-rich sandstone/sandy tuff. Graded pebble-to-cobble conglomerate/ sandstone/sandy tuff rhythms $(\mathrm{Gcm} / \mathrm{Sh})$ can be seen thinning out basinwards, to the N-NE. (F) Cycles (pebble-to-cobble conglomerate/ sandstone/sandy tuff which show graded bedding. White arrows indicate crosscutting Mn-rich veinlets. 

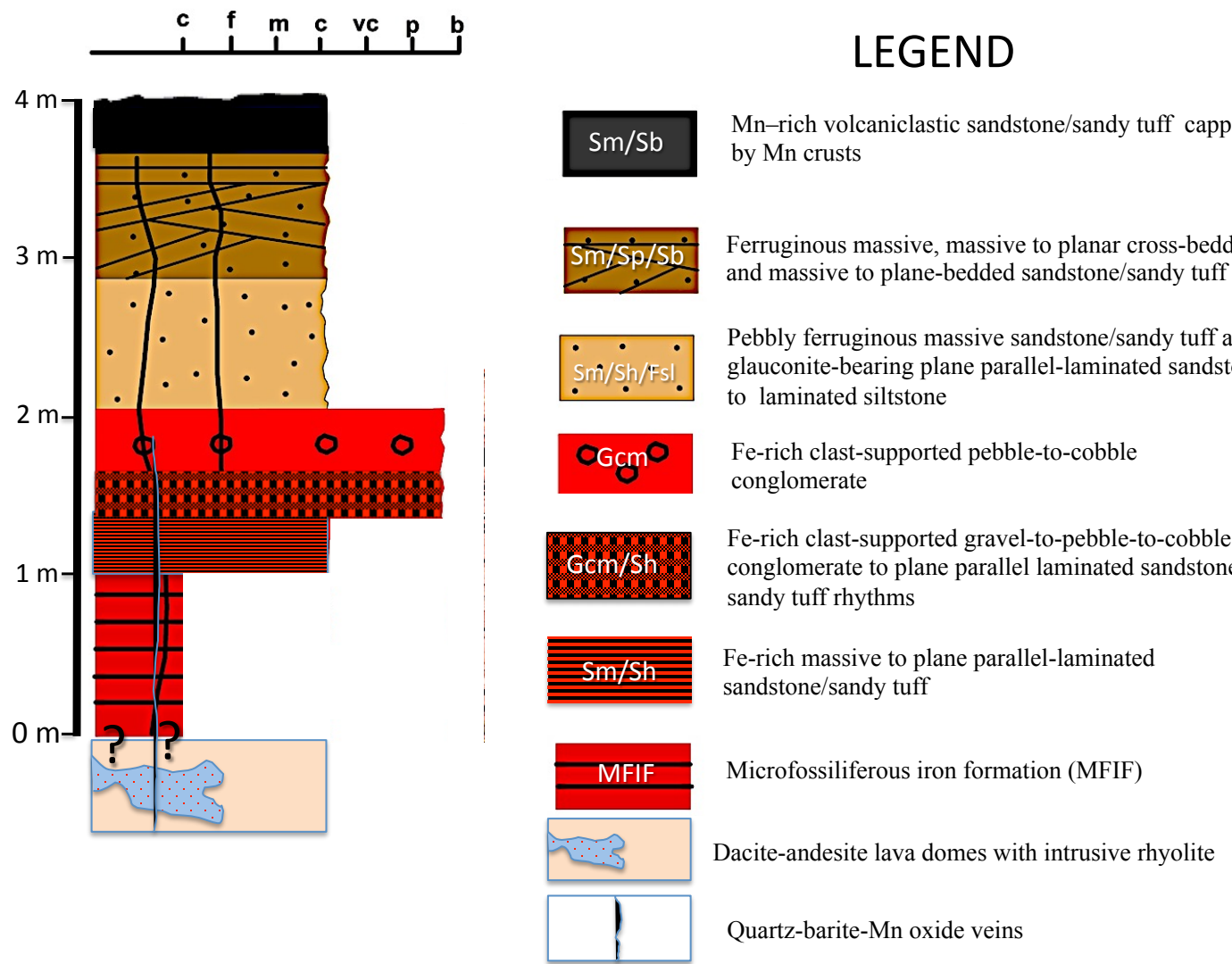

\section{LEGEND}

Mn-rich volcaniclastic sandstone/sandy tuff capped by Mn crusts

Ferruginous massive, massive to planar cross-bedded

Pebbly ferruginous massive sandstone/sandy tuff and glauconite-bearing plane parallel-laminated sandstone to laminated siltstone

Fe-rich clast-supported pebble-to-cobble

Fe-rich clast-supported gravel-to-pebble-to-cobble conglomerate to plane parallel laminated sandstone/ sandy tuff rhythms

parallel-laminated sandstone/sandy tuff

Supplementary Fig. 2. Measured stratigraphic section A containing the microfossiliferous iron formation (MFIF) lithofacies at the base, that is correlatively interpreted to be in direct stratigraphic contact with Late Pliocene-Early Pleistocene (2.5-1.5 Ma) basement submarine dacitic-andesitic rocks. See Figure 1 for location. 

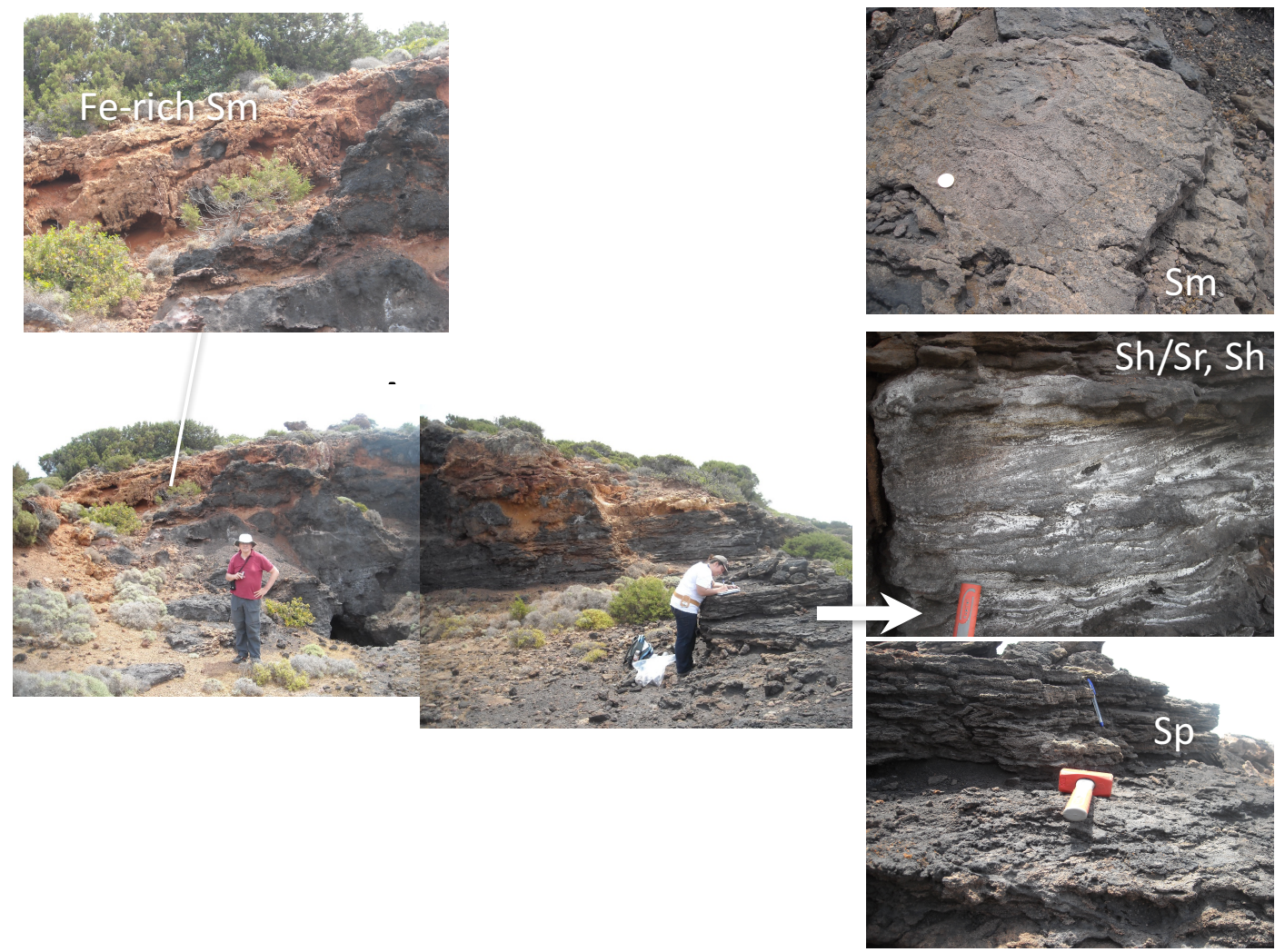

Supplementary Fig. 3. Field photographs from the Section B ("Magnus Hill") showing lithostratigraphic unit A (light gray Mn-rich sandstone in Supplementary Figure 4). Sm: Massive sandstone. Sh/Sr: Plane parallel laminated to rippled sandstone. Sh: Plane parallel sandstone. Sp: Plane cross-bedded sandstone. 


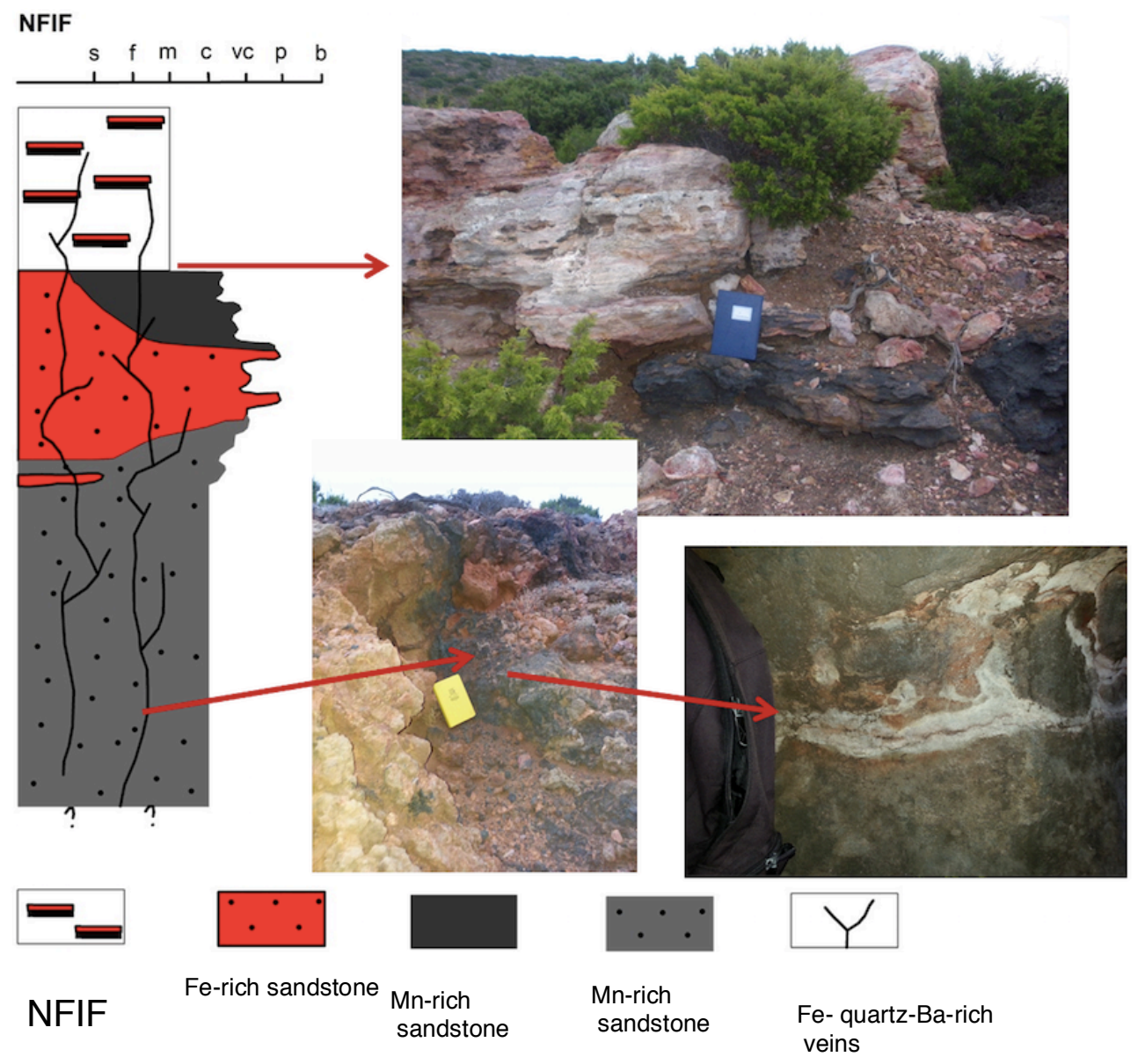

Supplementary Fig. 4. Field photos showing the stratigraphy of the exposed NFIF 


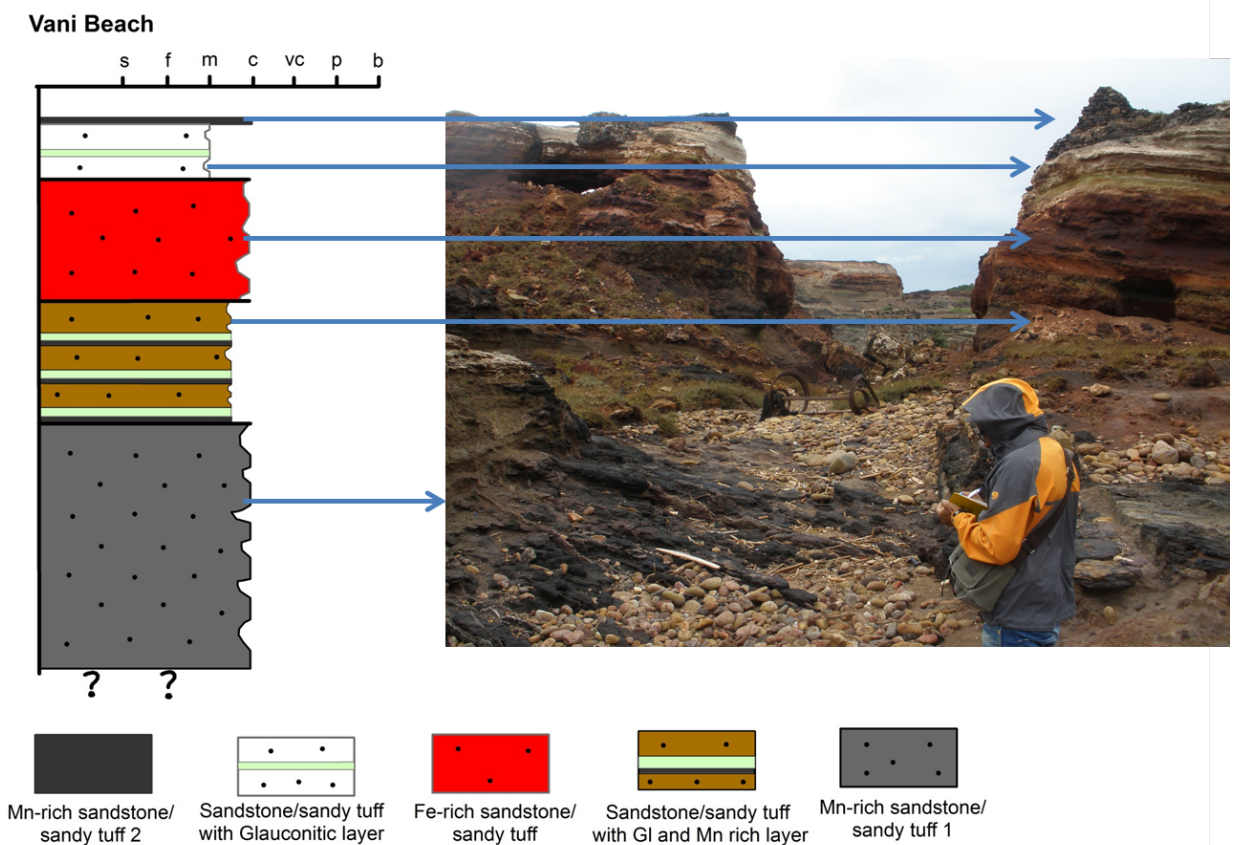

Supplementary Fig. 5. Field photo showing the stratigraphic section of the exposed Mn mine proximal to the Aegean Sea 


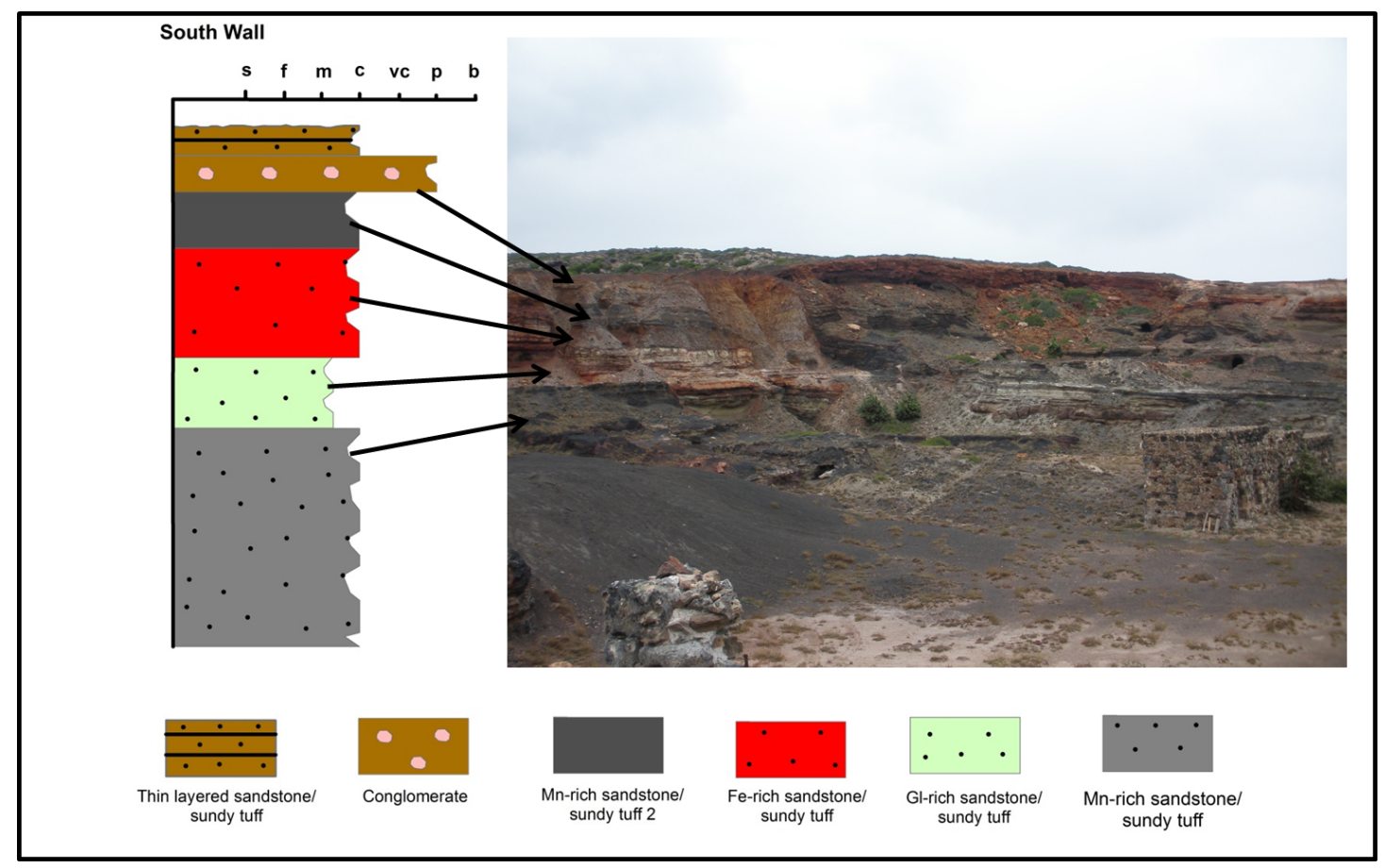

Supplementary Fig. 6. Field photo showing the stratigraphic section of the exposed Mn mine on the South wall of the open mine pit 


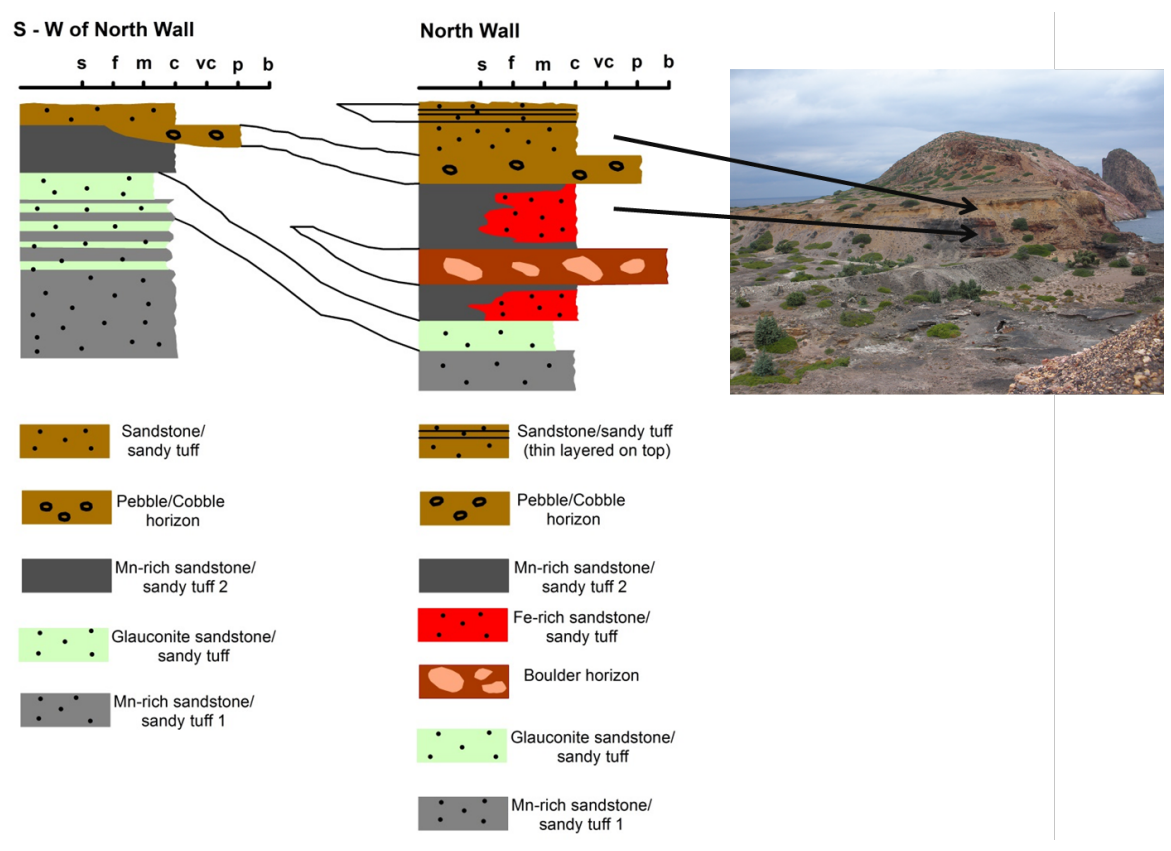

Supplementary Fig. 7. Field photo showing the stratigraphic section of the exposed Mn mine on the north wall of the open mine pit. 

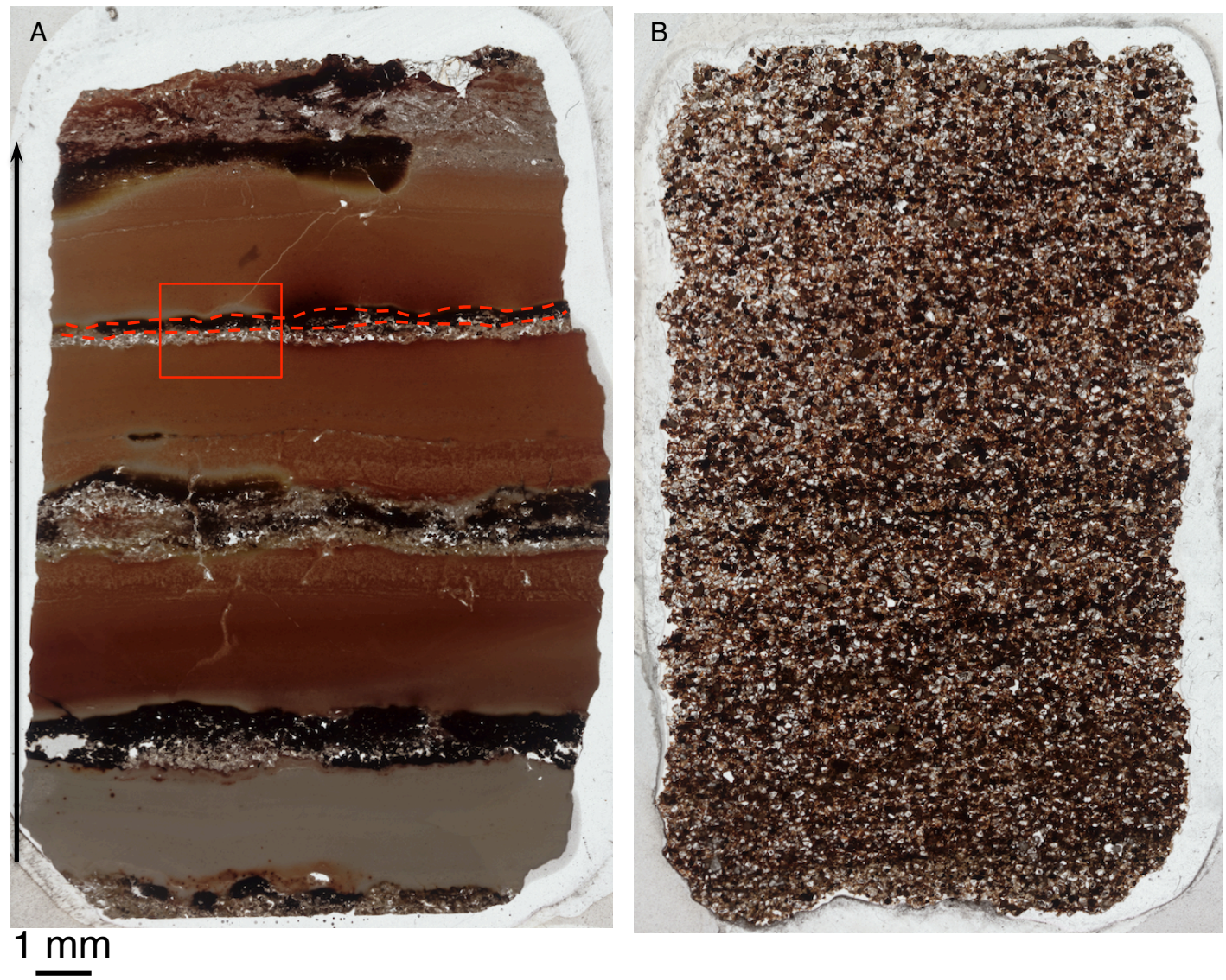

Supplementary Fig. 8. Photographs of the alternating Fe and Si-rich rocks (A) and a typical sandstone hosted Fe-rich deposit (B). The arrow indicates the proposed direction of sedimentation, revealed by size-dependent settling of particle sizes in the Fe-rich layers as shown in the magnification of the area in the red rectangle in supplementary Figure 9. Notice the extreme fine texture of the laminated Si-rich layers compared to the coarse sand grains in panel B. The coarse debris in the Fe-rich layer is composed of volcaniclast, whose size fraction is below the range classified as sand. Red dotted line shows an example of a dark dense hematite-rich band characterized by a low volcaniclast content as explained in supplementary Figure 9. 

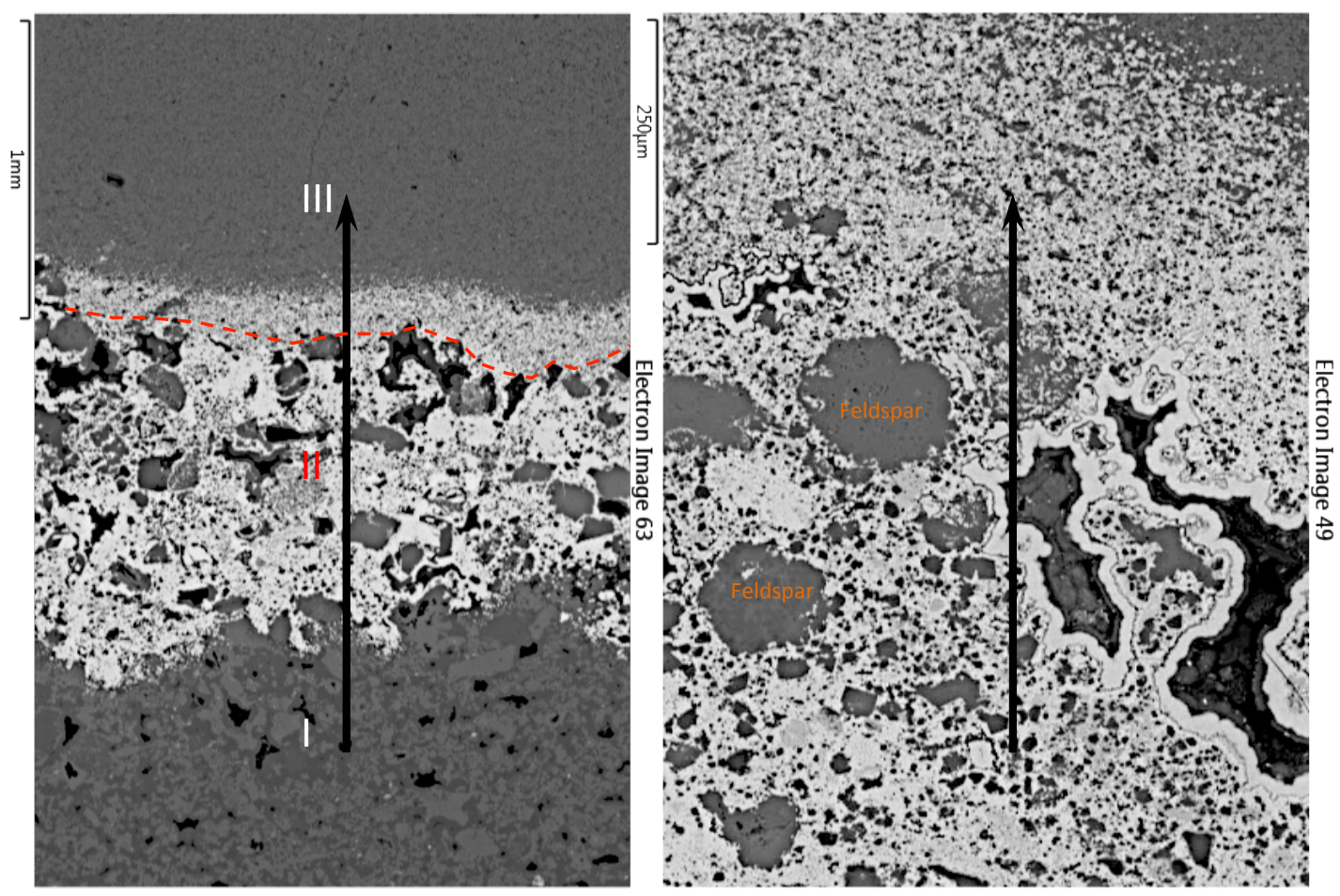

Supplementary Fig. 9. Magnified electron image of the thin section presented in Figure 8A, showing the size and types of particles present in the Fe- and Si-rich layers. Magnification shows the complete absence of typical sand grain-sized textures, with the white nano-hematite particles occurring together with volcaniclastic (feldspar). The larger volcaniclast are mainly prevalent in the Fe-rich layers (II). Nano-scale examination of the alternating layers with SEM and TEM reveals that sand, if any at all, constitutes a minor component of these layers, especially when compared to the typical texture of the sandstones hosting iron-rich coatings (Supplementary Fig. 6B). According to the Krumbein phi scale for very coarse, coarse, medium-grain, fine and very fine-grained sand should fall in the range of 1000-2000 $\mu \mathrm{m}, 500-1000 \mu \mathrm{m}, 250-500 \mu \mathrm{m}, 125-250 \mu \mathrm{m}$ and 62.5-125 $\mu \mathrm{m}$, respectively. The particle sizes within the MFIF and NFIF are below the Krumbein phi scale range for sand grains and are associated with feldspars of volcanic origin. The sizes of both the Si and Fe-rich particles are as would be expected in the chemical mud deposits that formed typical Precambrian BIFs. Notice that the volcaniclastic particles vanish as we progress from layer II to III. Towards the top of layer II, indicated by the red dotted line, the large volcaniclast particles disappear, leaving behind mostly fine-grained hematite particles, indicating termination of the exhalative hydrothermal phase, giving room for fine Si to settle out of the water column to form the Si-rich layer, followed by a new cycle of hydrothermal exhalation, introducing new iron into the water column. This pattern is also emphasized in Supplementary Figure 8, progressing in the direction of the arrow. The darker layers in the Fe-rich bands are hematite dense. This consistent pattern suggests the Fe-rich bands are 
formed during periods of active hydrothermal exhalation accompanying submarine volcanism, mixed with a process in the water column that oxidizes $\mathrm{Fe}^{2+}$, precipitating it alongside the volcaniclast particles onto the seafloor. This would be similar to how the Algoma-type BIFs formed. Secondly, the observation indicates that sedimentation within a water column environment where the heavier volcanic particles settled first, coincided with water column oxidation of a new wave of $\mathrm{Fe}^{2+}$ supply. 


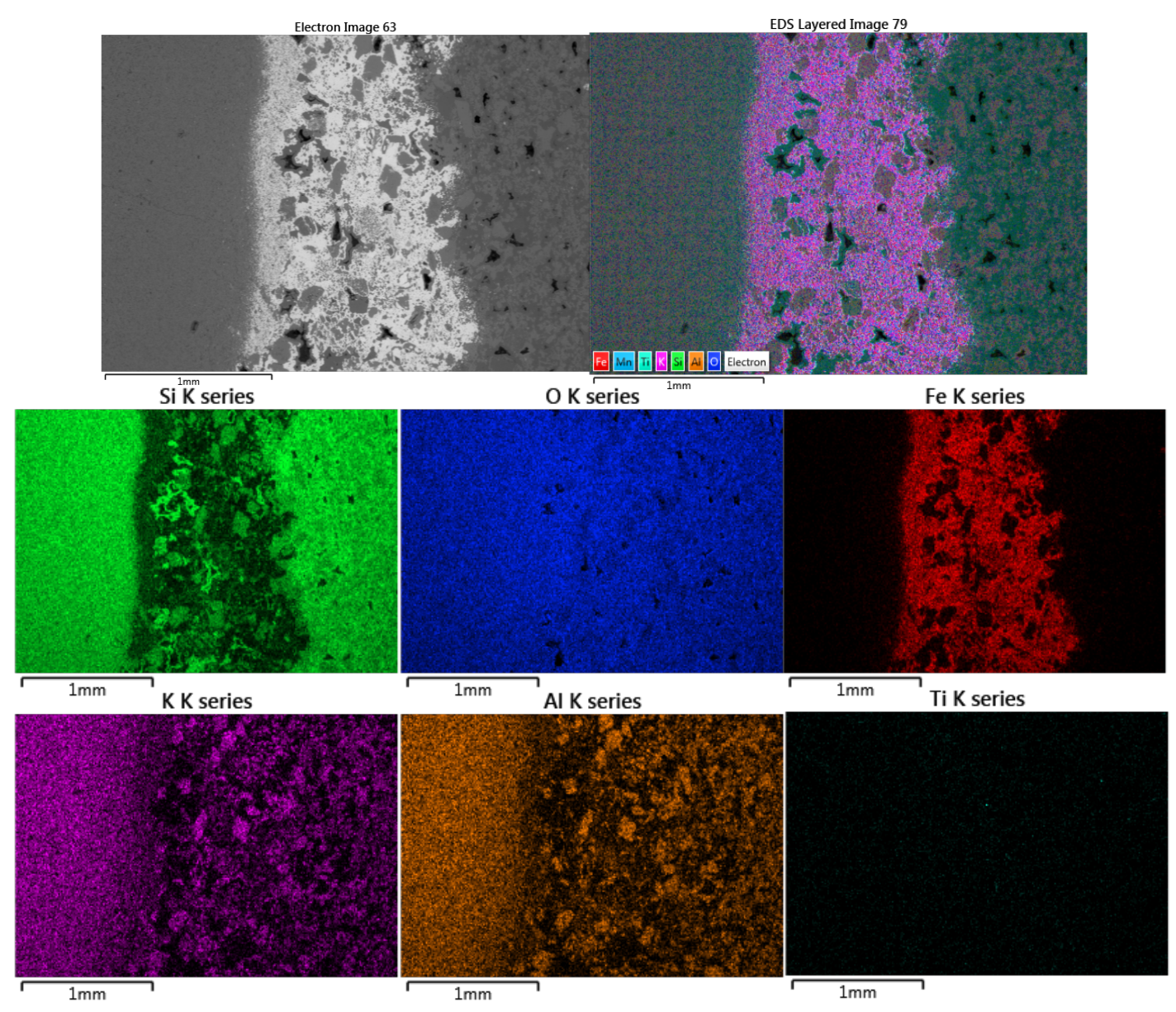

Supplementary Figure 10. Electron maps for a Si/Fe alternating band from the NFIF. A map sum of the spectrum suggests a relative elemental composition for $\mathrm{O}, \mathrm{Si}, \mathrm{Fe}, \mathrm{K}$ and $\mathrm{Al}$ of 42.8, 29.8, 16.3, 6.0 and $4.9 \mathrm{wt} \%$, respectively, with Ti and Mn making up a negligible $0.1 \mathrm{wt} \%$ each. 


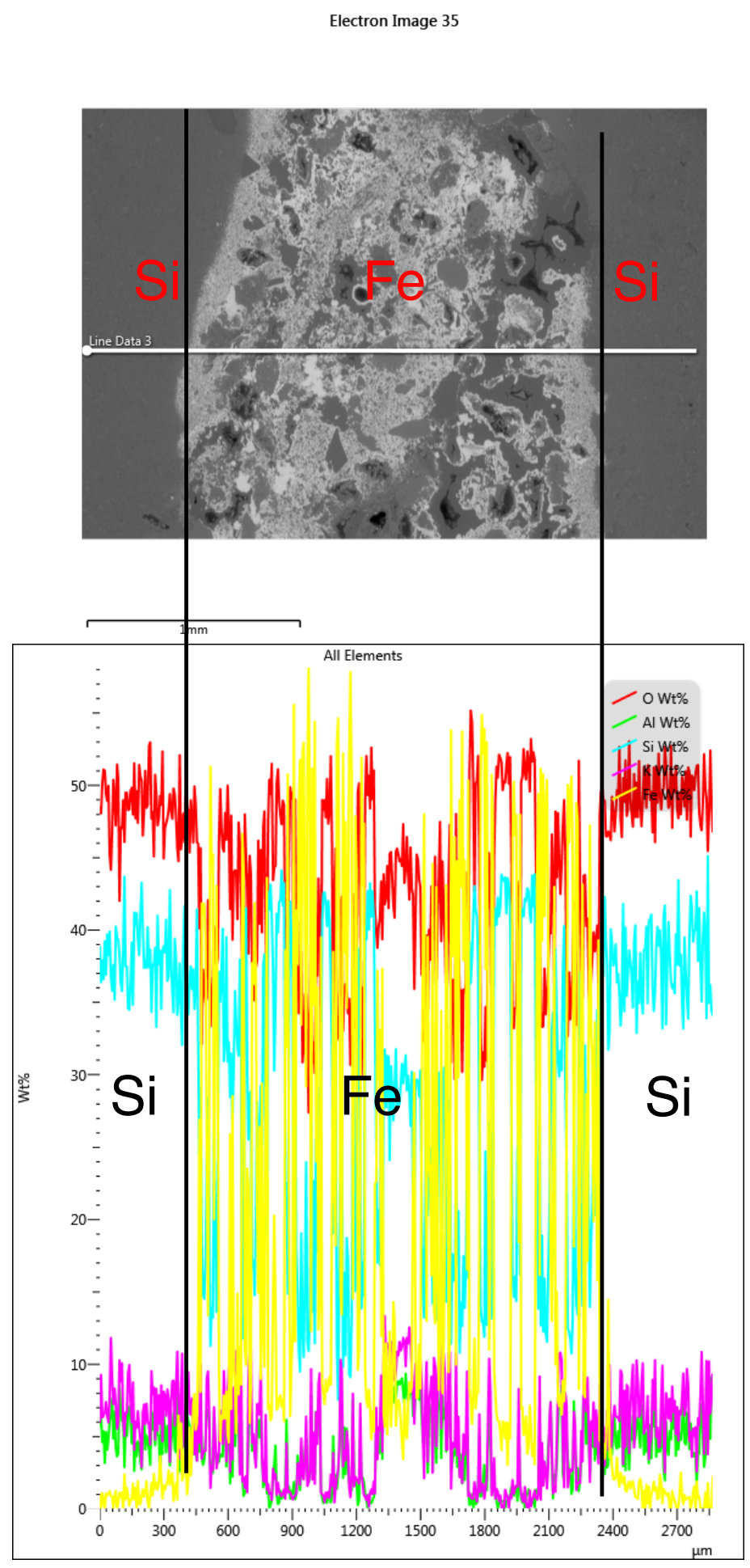

Supplementary Fig. 11. SEM-EDS line scan across a Si/Fe-rich band described in supplementary Figure 8 and 9 above, showing the relative elemental composition of $\mathrm{O}, \mathrm{Al}, \mathrm{Si}, \mathrm{K}$ and Fe. Notice the volcaniclastic fragments in the Fe-rich layer that are absent in the Si-rich band. 